\title{
A Design-Based Approach to Course Planning and Development ${ }^{1}$
}

\author{
Antti Rissanen ${ }^{2}$ and Kalle Saastamoinen ${ }^{3}$
}

\begin{abstract}
The aim to refine education often leads to changes to curriculums, and the planning and implementation of educational changes can be approached in methodological and process-oriented ways. This study investigated how Bologna process and local needs lead to a new implementation. Case material presents how courses were planned for the Department of Military Technology at the NDU. The data was gathered from three courses related to science and technology, and a design-based research (DBR) concept guided the project.

Specifically, work from 2007 to 2017 was examined, including preplanning and educational DBR cycles used to plan six courses, and team of different disciplines worked on the project. The purpose of planning courses was to construct a new science, technology, engineering, and mathematics (STEM) education program for officers' education; the aim was to offer officers adjustable but well planned, student centred, and interactive instruction. In principle, course planners were aware of the generic skill profile of the officer profession. Knowledge of STEM education from an earlier curriculum was provided to the officers by regular teachers. The use of a modern learning material portal (LMP) was considered for a student-centric teaching approach. Moodle was utilised, and a systematic student evaluation of teaching (SET) was conducted to assess the success of implementing the planned courses. DBR-framed approach gave useful guidance for the project. In the course development feedback from students offers necessary evidence but requires support from other sources for genuine and innovative educational re-engineering.
\end{abstract}

Keywords: design-based research, instruction, learning by doing, student evaluation of teaching (SET)

\section{Introduction}

Many courses in higher education are theory-oriented and have long histories of discipline-specific features (Winber, 2008). For example, the traditional curriculum approach relies on lectures, exercises, and summative tests (e.g. Black, 2002). In refining this concept for the digital age, supplemental materials are essential, especially for many university-level courses. However, some scholars claimed that without full curriculum revisions, such materials could not support self-directed learners. Thus, university education research considered pedagogical issues with instruction and assessment techniques as well as the use of alignment in educational practices. It was noted that according to the Bologna principles, a quality education means that student and process-quality challenges must be comprehensively considered (The Bologna Process, undated).

\section{Education Schedules}

The NDU is a training institution responsible for educating the future leaders of Finland's armed forces. Master-level studies at the NDU require previous education and a commitment to the profession. Studies in military sciences commence at the undergraduate level, and candidates for a

\footnotetext{
${ }^{1}$ This study is an extended version of a presentation held at the first International EDUREF Symposium, which was April 6-7, 2018 in Ankara, Turkey.

${ }^{2}$ National Defence University, Helsinki, Finland. mail:Antti.rissanen@mil.fi

${ }^{3}$ National Defence University
} 
Bachelor of Military Sciences degree serve as the rank of cadet. These cadets complete their bachelor's degrees in three years and then begin working in the Finnish Defence Forces. Instead of a permanent job, they receive a fixed-term junior officer's commission. (NDU, 2018)

The Bachelor of Military Sciences degree at the NDU comprises 180 ECTSs (European Credit Transfer and Accumulation System). In addition to these, undergraduate students complete 30 ECTSs, which are professional studies, to become qualified officers. The degree requirements include undergraduate STEM-related courses, which are relatively short and intense. Lectures and customized exercises are preferred for gaining or refreshing basic knowledge in these disciplines. Feasible, motivational, and deep learning experiences, such as miniature laboratories and work- and life-related field experimentation, are used to provide students with concrete learning experiences (Rissanen \& Saastamoinen, 2017).

The Master-level studies pre-planned schedule consists of advanced studies and a thesis. Significant subjects include compulsory and elective modules and methodology courses. In addition, students study minor subjects, including language and communication studies. Most studies are completed at the NDU, but some are completed in service-, branch-, and functional-area schools. Due to their preplanned unification with undergraduate studies, master's level theoretical STEM studies rely on undergraduate studies.

The Bologna declaration is a project to create a European Higher Education Area (EHEA) with a comparable system of academic standards and quality. On the other hand key issue in the local demand was to extend previous non standardized master level studies from one year long up to 6 semesters in two studying years. The NDU's updated Master in Military Sciences degree comprises 120 ECTSs. The primary goal was and is still to train officers for the Finnish Defence Forces and Border Guard. The master's degree and military vocational studies aim to provide students with the prerequisites needed to serve as leaders within emergency conditions and as commanding officers within normal conditions. The graduate program requires two years of full-time studies. (NDU, 2018) The learning aims for graduate students in technology may be divided into four related themes. The first two learning aims are scientific knowledge and an understanding of how technology utilises scientific results. The remaining two learning aims are the advanced ability to manage practical exercises and weapons-related research within a working environment and the ability to strengthen one's personal learning capabilities to ensure life-long learning.

This study examined three new science- and technology-related graduate courses at the NDU, which were planned and held in six times. In 2007, two years before the first implementation, a teacher team worked to construct a new STEM education program for officers' education. The curriculum was piloted between autumn 2009 and spring 2013 with three graduate courses; some technology-trained students from the preceding undergraduate program took the courses. Originally planned Bologna type student profile was available from the autumn 2013. Therefore, the updated standard plan was used from autumn 2013 to spring 2017, when the sixth master course was completed. Minor yearly modifications were made for each course. Additionally, during an implementation phase, an enhancement project was used to correct educational environments in regards to technical limitations that were not known before the courses were implemented.

\section{Purpose and Research Questions}

The educational environment of the NDU supports research. All technology and science courses at the university are relatively short and intensively scheduled, so they can be repeated with minor modifications each year and multiple changes can be studied. However, observations of different course iterations can be systematically analysed only after cumulative data is available. Moreover, some changes can be considered soon after a course ends because obligatory courses are taken by students in a specific order. 
In this study, different group work practices, examination protocols, and feedback were studied to obtain a comprehensive understanding of the learning environment, and course revisions were considered in regards to internal reporting. Three technology courses were observed from 2009 to 2017. This data was related to the structures of the studied courses and how teaching should be arranged in the future. During the observation period a total of 85 students participated in each of the three courses.

Quality systematic work was completed with Moodle, so a wide range of student evaluations regarding instructors' teaching practices and memorandums were available for studying the success of each course's implementation. As aforementioned, three graduate courses were piloted with technology-trained students who graduated from the preceding undergraduate program; the courses involved a new Bologna-type curriculum. Thereafter, three ordinary, i.e., original, courses with students having Bologna-type BA-studies were observed as controls.

The purpose of the study was to evaluate whether the content, structures, and instructional approaches of the courses would benefit from the DBR framework. To meet this purpose, the study included multiple research tools, such as questionnaires, participant reflections in focus groups, analyses of archived course scores, and supplementary interviews. Moreover, the study focused on valuing student feedback and framing the project in terms of DBR. SETs in higher education involve some challenges regarding validity (Spooren, 2013); conclusions reached with instruments that gauge students' attitudes depend on the quality of a study's method (Lovelace, 2013).

The study considered two research questions. The first was as follows: Can the cyclic nature of planning and implementation (DBR) be reflected in this systematic development project? The second was as follows: Can SETs be used for estimating success in curriculum planning and for driving corrective steps for successive courses?

\section{DBR as a supporting tool}

Higher education pedagogies are useful guidelines for good teaching practices and for framing work. For the research involved in this study, a pragmatic viewpoint was chosen. The research involved a DBR methodology, an approach based on multiple sub-processes with the intent of producing new theories, artefacts, and practices that impact learning and teaching settings (Cobb et al., 2003). This approach gained interest among educational researchers, e.g., Anderson and Shattuck (2012), as its purpose is to use a systematic but flexible methodology to enhance educational practices through iterative analyses, designs, developments, and implementations, based on collaboration among researchers and practitioners in real-world settings (Wang \& Hannafin, 2005).

DBR approaches are unique to each study and may utilise one or multiple iterative cycles with different phases of analysis, design, development, implementation, and evaluation. Such research does not exactly follow a guided methodology but is self-aligned in regards to teaching practices and questions based on teaching (Gravemeijer, 1994). However, instructional developments cannot be based on only empirical evidence because values define what is important in learning and teaching (Hammersley, 2002). As a conclusion when education is enhanced properly, scholars can speak about educational innovation creation. Innovative concepts should be expressed clearly so the novelty of the concepts can be accessed, but extra details that may limit teachers' own creativity and practices should be avoided (Millar 2010).

In science education, instructors are often simultaneously researchers; these instructors may be active scholars in learning material development and even authors and co-authors of study materials (Meisalo, 2007). Thus, communication between course coordinators, instructors, and students is essential when educational practices are developed. DBR projects may begin with undefined stages that teachers/researchers do not know how to continue forward. As figure 1 shows multiple things may be included for the project and the lifespan of a research project might be long. It is necessary to 
clarify problems and to question what kinds of opportunities and constraints are linked to activities. By answering these questions, research teams can determine what kind of problems educational innovations should address (Juuti \& Lavonen, 2013).

\section{Notes on the Method}

When planning the courses, the NDU's teachers were aware of the generic skill profile of the officer profession in regards to STEM education and the earlier curriculum. Moreover prior knowledge and some experience with a locally made LMP were gained, and earlier educational outcomes were summarised as inputs for the new implementation. Bologna process opened a true need for rethinking learning aims and links between each course in the curriculum. This meant that it was acceptable to spend more time on planning and need for writing more detailed description of the final learning aims before establishing the course structure. After documentation the planned courses were implemented. In recent research on Massive Open Online Course (MOOC) implementation the instructors' detailed workload has been pondered (Fini, 2009 also Parr, 2013).

Based on practical and workload related reasons a selective blended teaching approach was chosen for these courses. In-person lectures and guided exercises were emphasised in students' learning processes, and supplemental tasks were available through the portal. It should be noted that most education at the NDU included compulsory lecture and exercise attendance. The benefits of these traditional classes were considered, and adjustments were made to allow the deep but gradual utilisation of a common easy-access LMS, Moodle, (e.g. Dougiamas, 2004) with the courses.

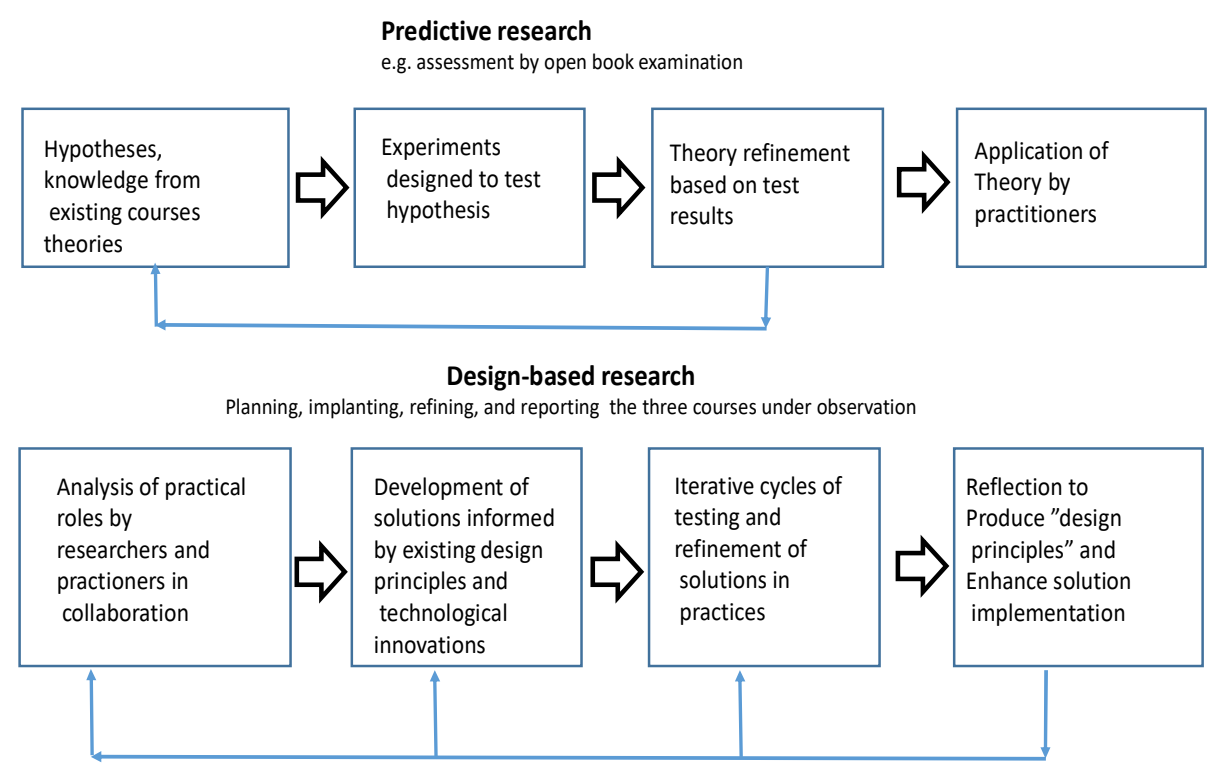

Figure 1. The cyclic nature and process type of classification. The DBR method described as a practical tool for solutions. (Amiel \& Reeves, 2008).

The first course implementation was a true pilot test. The test included many student-centric concepts involving specific themes, but some themes were omitted as the pilot-planning stage was not completed by the time decisions needed to be made in spring 2009. For example, the concept of using open book examinations (Rissanen, 2016) was previously tested, but not fully implemented in the first round. The first pilot test commenced in autumn 2009, and the NDU's administrators decided that the second pilot test would commence in autumn 2011. This provided one year to consider the first pilot test and revise it for the next implementation. For example, rapid technological developments in educational applications were considered to determine alternatives to traditional lectures before the 
course structure was stabilised. Assessments were modernised so teachers measured not only students' understanding of facts and basic skills but also students' ability to utilise knowledge (Henderson et al., 2012; Collins, 2013). Referring to the figure 1, assessment research was done as predictive research while the implementation of these courses was linked to DBR phase.

The DBR method involves the understanding that research has a cyclic nature. Thus, the study continued up to a sixth course implementation. However, it should be noted that after that the NDU's Department of Military Technology replaced two of the courses with more experimental professionoriented courses. From the observed three courses only the Simulation and Modelling Course remained as a graduate course for $7^{\text {th }}$ master course onwards. The graduate program was set to be redefined in autumn 2020.

\section{Course One: Geographic Information System Course (GISC)}

Geographic Information Systems are specific technologies that use data with information linked to a specific place or area (Longley, 2005). Military GIS education is an important subject and is part of both the undergraduate and graduate programs at the NDU. This study's GIS course focused on the technological aspects of modern GISs. The module had a significant hands-on component during which students learned how to use $\operatorname{ArcGis} \AA$, a digital geographic data tool. With support from topographic and cartographic Defence Forces personnel, students were taught to understand daily use and the potential offered by the technology. They learned how to extract information from databases, combine themes into layers, and represent data in the forms of specific maps, figures, diagrams, and reports. This knowledge related to strategic and tactical decisions, and the course's textbook, which was by Longley (2005), was used to widen students' perspectives. Assessments comprised three parts: group work on a provided theme, an open book examination, and short theme work evaluated by peers. The course included many student-centric teaching methods.

During each of the six implementations of this course, significant adjustments were needed. For example, in the beginning, demands were not well defined and were too significant for the students. Therefore, additional guidance and support materials were added to Moodle, and some English reading tasks were omitted. Moreover, assessment protocols were simplified. The utilization of ArcGis ${ }^{\circledR}$, was limited to demonstration of the software, and this was done with guidance from specialist engineers. More ambitious student-centric work towards demonstrations was related to how the software and students' computers were managed at the NDU; graduate students received a salary and all students were on duty, so all educational materials including computers were managed according to system rules. This made more limitations for software utilization than expected when main lines of the course were written.

\section{Course Two: Advanced Sensor Technology Course (ASTC)}

Surveillance and target acquisition information is mostly obtained with specific devices. In this course, students learned the science used for such devices. Based on this knowledge, students were able to understand principles related to practical performance standards and sensor comparisons. That is, they could gain environmental knowledge and understand tactical concepts, and could thus gain estimation capabilities for use with certain equipment in the future.

The fundamentals of electromagnetic spectrum environments, the fundamentals of sensors, and the current state of technology were taught. The course was built around lectures, visits to surveillance locations, theme videos, and homework. The homework had two parts. For the first part, groups made presentations on methods of surveillance. For the second part, students wrote essays on the topic. Assessments comprised three stages: group work on one theme, chosen from a list, with a presentation in the middle of the course; a technical report handed in using the educational portal, due two weeks from the last lecture day, and an experimental take-home exam that utilised Moodle (Rissanen, 2016). 


\section{Course Three: Simulation and Modelling Course (SMC)}

This course was used to explore how a relatively practice-oriented simulation course worked as a professional tool or as a master's thesis methodology choice as officers needed to be able to use theoretical knowledge in practice. Students learned that to understand various battlefield scenarios, as well as ways of utilising high-tech weapons, environments need to be modelled for observation. The course combined and extended basic algorithms and statistical models for practical Excel-based solutions which are able to simulate the given tasks. The instructional structure of the course consisted of three overlapping teaching methods: lectures, supervised exercises, and unsupervised exercises. At the end of the course, student groups made presentations on unsupervised exercises. Final reports were also made; these assignments consisted of documentation and functional simulations completed by the groups.

In order to encourage students to learn practical skills, specific simulation and modelling themes were provided: how real-world artefacts and models work; how data can be acquired; how acquired data can be visualised; and how to further one's understanding of a topic using simulations. Exercises, homework, and reports were completed by mostly small student groups. The course ended with the aforementioned group work, for which students produced a working simulation model either from a provided list or based on their professional contexts. The course's success was estimated using student reports and feedback. Instructors' observations of students' motivation and learning goal achievements were also considered and compared to other course data to revise the course for later iterations.

\section{Student Feedback Results and Analyses}

Observations focused on the learning results, motivational aspects, and common impressions of the courses. Standard local SET questionnaires in Moodle were used for data collection, data comparisons, and data storage. The questionnaires involved a five-step scale, a psychometric scale that has five categories from which respondents choose to represent their attitudes and opinions about particular issues. When data from such questionnaires, which is quantitative, is combined with qualitative data, such as data gathered using open-ended questions, participant observations, and interviews, the questionnaires' validity is improved and results become more concrete than they would be otherwise. On the scale, five denotes 'agree' and is the highest grade, and one denotes 'disagree' and is the lowest grade.

Table 1. Students' Evaluations of the Sixth Implementation of the Three Courses

\begin{tabular}{lccc}
\hline $\begin{array}{l}\text { Standard Questions Given to the Students in the Sixth } \\
\quad \text { Implementation (internal code: } S M-6 \text { ) }\end{array}$ & GISC & ASTC & SMC \\
\hline I achieved the goals set for the course. & 4.4 & 4.0 & 3.9 \\
I was an active learner. & 3.8 & 4.0 & 3.9 \\
The learning atmosphere supported my learning. & 4.7 & 4.5 & 4.0 \\
The instructors mastered the facts. & 4.8 & 4.8 & 4.5 \\
My overall grade for teachers & 4.5 & 4.4 & 3.7 \\
The course provided me with new knowledge; it was not just & 4.7 & 4.5 & 4.6 \\
a repetition. & 4.5 & 4.3 & 3.9 \\
The assessments supported my learning. & 4.3 & 4.0 & 4.2 \\
The LMP was utilised well. & 4.0 & 4.2 & 4.0 \\
The course's demands and credit units fit each other. & 4.5 & 4.2 & 3.9 \\
My overall grade for the course as a whole, on a scale of one & & & \\
to five. & 17 & 12 & 16 \\
\hline$N$
\end{tabular}

Note. This table shows the 10 most development centric questions out of 21 questions total. 
Table 1 shows that after revising the courses, they were well established. The variations in answers for the three courses were noted, but discussions with students and researchers did not fully explain the reasons for differences. Interviews suggested, but did not prove, that the differences were based on the teachers' personal teaching paradigms. However, it should be noted that the study revealed how important or interesting the contents of the courses were perceived and how the students appreciated the teaching themes in regards to their professional ambitions.

Table 2. Students' Evaluations of the ASTC

\begin{tabular}{lcccc}
\hline Standard Questions Given to the Students in the ASTC & $\begin{array}{c}\text { Third } \\
\text { Iteration }\end{array}$ & $\begin{array}{c}\text { Fourth } \\
\text { Iteration }\end{array}$ & $\begin{array}{c}\text { Fifth } \\
\text { Iteration }\end{array}$ & $\begin{array}{c}\text { Sixth } \\
\text { Iteration }\end{array}$ \\
\hline I achieved the goals set for the course. & 3.6 & 3.8 & 3.6 & 4.0 \\
I was an active learner. & 3.6 & 3.5 & 3.5 & 4.0 \\
The learning atmosphere supported my learning. & 4.1 & 4.0 & 4.4 & 4.5 \\
The instructors mastered the facts. & 4.6 & 3.9 & 4.0 & 4.8 \\
My overall grade for teachers & 4.0 & 3.4 & 3.0 & 4.4 \\
$\begin{array}{l}\text { The course provided me with new knowledge; it was } \\
\text { not just a repetition. }\end{array}$ & 4.5 & 3.6 & 4.6 & 4.5 \\
The assessments supported my learning. & 4.4 & 3.7 & 3.0 & 4.3 \\
$\begin{array}{l}\text { The course demands and credit units fit each other. } \\
\text { The LMP was utilised well. }\end{array}$ & 4.3 & 3.5 & 4.4 & 4.2 \\
My overall grade for the course as a whole on a scale \\
of one to five.
\end{tabular}

Note. This table shows only voluntarily given answers.

Table 2 shows that the pilot course performed favourably. Then, the results for the first two iterations decreased; open-ended questions suggested why. A significant number of the students had studied surveillance- and target acquisition-related tasks in the Finnish Air Force and the Finnish Navy, so they had asked to further their existing knowledge. However, some Finnish Army students had not gained such background knowledge and needed to take the course before learning about the technology behind other devices. Thus, these two implementations were unsuccessful and linked to more detailed student profile work.

For the sixth implementation, the course and tasks were summarised more effectively and allowed for more detailed differentiations according to student groups' work-life profile. Open-ended questions and discussions with students address more on the course's strategies and resources rather than course's content and tools in instruction (e.g., how to allocate working hours, and how to increase flexibility in courses). Further researches on interventions like team of instructors in seminars will be studied in the simulation course.

\section{Voice of students' and DBR Framing in Regards to Course Enhancement}

As aforementioned, the study loosely followed a DBR framework; it provided a structure useful for long-term educational development. Such development is typically iterative work, and real educational improvements can be obtained with the persistent cooperation of team members. Aside from the ability to focus on practical tasks, this method focuses on theoretical problem analyses, and it in turn helps scholars to consider meaningful issues in the field, e.g., commonly known evidence and knowledge of teamwork challenges.

Feedback from students with SET provides necessary information for instructors regarding how to streamline teaching protocols, but it provides only a few tools for making significant educational 
improvements. Therefore, development work in this field requires more than only empirical evidence of learning results and students' wishes and opinions. Technology development offers also new opportunities to organise education in a rewarding way and real innovations in this area require more than gathered formal feedback. The responsibility to re-engineer education in a creative way means for instructors and organisations a continuous challenge.

In DBR, the cooperation of different groups is emphasised. This means that the role of students should consider more than what student evaluation of teaching (SET) means with the analysis of such data. Space is needed for clarifying conversations and for other kinds of qualitative data with which instructors can determine problem areas. "Voice of customers" is valuable but in educational development space is also needed for deeper innovations. For such work simplified feedback from students forms seldom the main input. Empirical evidence can assist with determining important problem areas but may be insufficient for determining the most prominent targets for educational development.

\section{Conclusion}

In this study, six full courses based on the Bologna Declaration principles were implemented and investigated using the aforementioned method. The Bologna process had a minor influence in the contents work because there was discipline specific data available from various sources. Thinking of resource allocation, it truly opened possibility to make the planning properly with university pedagogical principles in mind. This research investigated the courses with relatively small groups, i.e., course groups of seven regular students and seven air-force pilot students of military technology; as the largest observed group consisted of 23 students. The volume will increase to over 50 students per course in autumn 2018. That in mind, the students' learning environments will be improved using precise, pre-planned and student centred interactive instruction. As an example, group works and student presentations are guided by a team of instructors.

Typically, group-based methods require proper group dynamics, honest assessment methods, and efficient instruction, particularly when in-person lectures are limited. Moreover, group work is not necessarily helpful only with motivational and activation tasks. Guidance and well-expressed aims for groups are needed to ensure success with group-based learning (Chiriac, 2014). Developing traditional in-person lectures in any knowledge-intensive course means always challenges. With large groups, all changes require sufficient attention to guidance and existence of a supportive control.

As aforementioned, this study's observations focused on the learning results, motivational aspects, and common impressions of the courses. For the trusted course environments, SETs were useful tools. The 5-step scales quantitatively measured students' opinions, and open-ended questions expanded the data. Further, with the NDU's atmosphere, every opinion was valuable. The standard local SET questionnaire utilizing Moodle was not created for the study, but additional measures made it a valuable quantitative tool. Each semester, qualitative data was gathered from multiple sources and verified with stakeholders. Moreover, real inputs were used for future course implementations.

\section{References}

Amiel, T., \& Reeves, T. C. (2008). Design-based research and educational technology: Rethinking technology and the research agenda. Educational Technology and Society, 11(4), 29-40.

Anderson, T., \& Shattuck, J. (2012). Design-based research: A decade of progress in education research? Educational Researcher, 41(1), 16-25.

Black, G. (2002). A comparison of traditional, online, and hybrid methods of course delivery. Journal of Business Administration Online, 1(1), 1-9. 
Bologna Process and the European Higher Education Area. (Undated). Retrieved from: http://ec.europa.eu/education/policy/higher-education/bologna-process_en

Fini, A. (2009). The technological dimension of a massive open online course: The case of the CCK08 course tools. The International Review of Research in Open and Distributed Learning, 10(5).

Cobb, P., Confrey, J., DiSessa, A., Lehrer, R., \& Schauble, L. (2003). Design experiments in educational research. Educational Researcher, 32(1), 9-13.

Collins, R. (2013). Authentic assessment: Assessment for learning. Curriculum and Leadership Journal, 11(7).

Gravemeijer, K. P. E. (1994). Developing realistic mathematics education [Ontwikkelen van Realistisch Reken/wiskundeonderwijs]. CD- $\beta$ Press.

Chiriac, H. E. (2014). Group work as an incentive for learning: Students' experiences of group work. Frontiers in Psychology, 5, 558. http://doi.org/10.3389/fpsyg.2014.00558

Dougiamas, M. (2004). Moodle: A virtual learning environment for the rest of us. TESL-EJ, 8(2), 1-8.

Hammersley, M. (Ed.). (2002). Educational research, policymaking and practice. Sage.

Henderson, C., Dancy, M., \& Niewiadomska-Bugaj, M. (2012). Use of research-based instructional strategies in introductory physics: Where do faculty leave the innovation-decision process? Physical Review Special Topic: Physics Education Research, 8(2), 020104.

Juuti, K. \& Lavonen, J. (2013). Design tutkimukseen osallistuvien opettajien rooli tutkimuksen eri vaiheissa. In J. Pernaa (Ed.), Kehittämistutkimus opetusalalla, (pp. 45-67). Jyväskylä, PS-kustannus.

Longley, P. (2005). Geographic information systems and science. John Wiley and Sons.

Lovelace, M. et al. (2013). Best practices for measuring students' attitudes toward learning science. CBE: Life Sciences Education, 12(4), 606-617.

Meisalo, V. (2007). Introduction to design research approach in producing learning material. IPUC TFPC Nicolaus Copernicus University, Poland, 27.4.2007 Retrieved from: http://fizyka.umk.pl/ scimath/DesignResearchApproach.pps

Millar, R. (2010). Using research to improve practice in science education: Where should we begin and what should we aim to produce? Designing Theory-Based Teaching-Learning Sequences for Science Education, 55.

Parr, C. (2013). Mooc creators criticise courses' lack of creativity. Times Higher Education, 17(03).

NDU (2018). Retrieved from: http://maanpuolustuskorkeakoulu.fi/en/frontpage

Rissanen, A. (2016). Developing an open book examination in a sensor technology course. International Journal of Information and Education Technology, 6(2), 148-152.

Rissanen, A., \& Saastamoinen, K. (2017). Remarks on Assessment in Cadets Common Technology Courses in NDU. International Journal of Information and Education Technology, 7(10), 743-748. 
Rissanen \& Saastamoinen (2018). Education Reform Journal, 2018, 3(2), 78-87

Spooren, P. et al. (2013). On the validity of student evaluation of teaching: The state of the art. Review of Educational Research, 83(4), 598-642.

Wang, F., \& Hannafin, M. J. (2005). Design-based research and technology-enhanced learning environments. Educational Technology Research and Development, 53(4), 5-23.

Winberg, C. (2008). Teaching engineering/engineering teaching: Interdisciplinary collaboration and the construction of academic identities. Teaching in Higher Education, 13(3), 353-367. 